\title{
Evaluation of Pregnancy Outcomes in Gestational Diabetes Mellitus
}

\author{
Lakshmi Sunar ${ }^{1}$, Zhu Yan ${ }^{2}$ \\ ${ }^{1}$ Department of Obstetrics and Gynaecology, Western Regional Hospital, Pokhara Academy of Health Sciences, Pokhara, \\ Gandaki, Nepal \\ ${ }^{2}$ Department of Obstetrics and Gynaecology, First Affiliated Hospital of Liaoning Medical University,Jinzhou, \\ Liaoning, P.R.China
}

\section{Corresponding author: \\ Dr. Lakshmi Sunar, MD \\ Obstetrician \& Gynaecologist \\ Department of Obstetrics and Gynaecology \\ Pokhara Academy of Health Sciences \\ Western Regional Hospital \\ snrlakshmi1216@gmail.com}

Article recived : 17th Jan. 2018

Article accepted : 4thOct. 2018

\begin{abstract}
Objectives: To evaluate the pregnancy outcomes in the patients diagnosed with Gestational Diabetes Mellitus.

Materials and Methods: A retrospective study conducted on ninety-two patients, delivered in the First Affiliated Hospital of Liaoning Medical University, China from February 2014 to June 2015.

Results: The rate of Cesarean section was $36.95 \%$, polyhydramnios $27.17 \%$, macrosomia $21.73 \%$ and preterm delivery was $14.13 \%$ respectively.

Conclusion: Gestational Diabetes Mellitus is recognized to be associated with increased rate of adverse pregnancy outcomes. This study demonstrated that the GDM has higher risk for polyhydramnios and macrosomia.

Key words : Blood glucose, Gestational Diabetes Mellitus, Pregnancy outcome.
\end{abstract}

\section{MATERIALS AND METHODS}

A retrospective study conducted on ninety-two patients, delivered in the First Affiliated Hospital of Liaoning Medical University, China from February 2014 to June 2015. Selected patients were Chinese Asian with the mean age of $28.98 \pm 3.23$. All the medical records, increased blood glucose levels and the pregnancy outcomes such as Cesarean section, preterm delivery, polyhydramnios and macrosomia were thoroughly reviewed. If the Fasting blood sugar level $>5.55 \mathrm{mmol} / \mathrm{L}(>100 \mathrm{mg} / \mathrm{dl})$ and Postprandial sugar level $>7.77 \mathrm{mmol} / \mathrm{L}(>140 \mathrm{mg} / \mathrm{dl})$ then the patient was confirmed as GDM and selected for the study. Inclusion criteria:

$\otimes$ Singleton

$\bowtie$ Gestational week $>28$ weeks

$\otimes$ Fasting blood sugar level $>5.55 \mathrm{mmol} / \mathrm{L}(>100 \mathrm{mg} / \mathrm{dl})$

$\otimes$ Postprandial sugar level $>7.77 \mathrm{mmol} / \mathrm{L}(>140 \mathrm{mg} / \mathrm{dl})$

Exclusion criteria:

$\otimes$ Multiple gestations

$\otimes$ Previously known history of DM 
The collected data were compiled, tabulated and analyzed using appropriated statistical test. All statistical analyses were performed using SPSS version 22 software. The different study variables were analyzed using descriptive statistics.

\section{RESULTS}

In this study ninety-two patients, who meet the inclusion criteria were selected, with mean age of $28.98 \pm 3.23$ years. Among these population $61.95 \%$ (57/92) were primi gravida and $38.04 \%$ (35/92) were multi gravida. The mean week of gestation was $36.41 \pm 2$.13. GDM was diagnosed on $25.5 \pm 1.6$ week of gestation. Mean Fasting blood sugar level was $5.4 \pm 1.13 \mathrm{mmol} / \mathrm{L}$ and postprandial sugar level $8.53 \pm 1.18 \mathrm{mmol} / \mathrm{L}$.

Table 1. Patients demographic features and outcomes

$\begin{array}{lc}\text { Details } & \mathbf{n}(\%) / \text { Mean } \pm \text { SD } \\ \text { Total number of patients } & 92(100 \%) \\ \text { Age in year } & 28.98 \pm 3.23 \\ \text { Gravidity: } & \\ \quad \quad \text { Primi } & 87(61.95 \%) \\ \quad \text { Multi } & 35(38.04 \%) \\ \text { Gestational week } & 36.41 \pm 2.13 \\ \text { GDM Diagnosed gestational week } & 25.5 \pm 1.6 \\ \text { Fasting blood sugar level (normal } 4-5.5 \text { mmol/L) } & 5.4 \pm 1.13 \\ \text { Postprandial sugar level (normal <7.8 mmol/L) } & 8.53 \pm 1.18 \\ \text { Outcomes: } & \\ \text { Cesarean section } & 34(36.95 \%) \\ \text { Preterm delivery } & 13(14.13 \%) \\ \text { Polyhydramnios } & 25(27.17 \%) \\ \text { Macrosomia } & 20(21.73 \%)\end{array}$

This study showed the rate of polyhydramnios was $27.17 \%$ (25/92), macrosomia was $21.73 \%$ (20/92), preterm delivery was $14.13 \%$ (13/92) and Cesarean section was $36.95 \%$ (34/92).

\section{DISCUSSION}

The term GDM was first coined by Pedersen in $1951 .^{7}$ GDM remains an area of controversy and debate in spite of extensive investigation into the condition. The most recent research relating to GDM, determines the association of maternal hyperglycaemia with an increased risk of adverse pregnancy outcome and ascertaining whether treatment of the condition can decrease perinatal morbidity. ${ }^{8}$ The increasing prevalence of gestational diabetes and its effects for individual mothers and infants and its impact on public health has become the major concern. ${ }^{9}$ The Hyperglycemia and Adverse Pregnancy Outcome (HAPO) study has shown significant independent association of higher maternal glucose concentrations with adverse pregnancy outcomes. ${ }^{10}$ Women with GDM in the present study were found to have higher proportion of obstetric complications including Cesarean section, preterm delivery, polyhydramnios, and macrosomic babies.

Various studies have reported that the rate of Cesarean section in GDM patients is very high despite maternal blood glucose control during pregnancy. ${ }^{11,12}$ Meanwhile, this study revealed that the rate of Cesarean section is $36.95 \%$. In this study the main indications for caesarean Section were macrosomia, polyhydramnios and patients choice. Caesarean delivery has been a common practice in China, local attitudes towards the caesarean delivery was better for baby and mother. Besides, social factors such as not bing able to bear the labor pain, worrying about the incision in perineum, misconception that vaginal delivery might affect sexual life, and fear of delivery failure leads to increased rate of Cesarean section. Especially following the implementation of the "One Child Policy" in China, the rate of Cesarean section is highly increased.

In this study, we found that GDM was associated with an increased risk of polyhydramnios and preterm birth. Inadequately managed GDM is associated with macrosomic fetus and polyhydramnios, but the pathogenesis has not been elucidated yet. ${ }^{13}$ One likely cause is fetal hyperglycemia resulting in increased osmotic diuresis which later leads to polyuria and afterward leading to polyhydramnios. This phenomenon is supported by a strong association with high glycosylated hemoglobin values in cases with polyhydramnios. ${ }^{13,14}$ According to Dutta, polyhydramnios may lead to preterm delivery, ${ }^{15}$ and in this study we found most preterm delivery is closely associated with polyhydramnios. The mechanisms behind these findings are unclear. This finding might just be a coincidence due to small sample size so further studies with large sample is required to verify our findings.

Glucose is transported freely across the placenta. In the case of increased level of blood glucose in mother, large amount of glucose is transported to the fetus, causing fetal hyperinsulinemia, which leads to fetal overgrowth and/or macrosomia. ${ }^{16}$ Macrosomia is 
associated with many obstetric complications, such as higher rate of Cesarean section, shoulder dystocia, chorioamnionitis, severe perineal lacerations, and postpartum hemorrhage. ${ }^{17}$ It is possible that, fasting blood glucose is difficult to be maintained below the threshold which persistently increases and large amount of glucose is transported to the fetus ultimately lead to macrosomia. Some authors showed a very strong correlation exist between the fasting glucose concentration above $5.82 \mathrm{mmol} / \mathrm{L}$ and maternal-perinatal complications, such as fetal macrosomia, cesarean delivery, neonatal hypoglycemia, hypertensive syndromes. ${ }^{18}$ Sacks and colleagues were among the first to describe the relationship between maternal glucose levels and birth weight centiles. ${ }^{19}$ However, these authors could not establish any significant threshold for diagnosis. So according to Sacks, any proposed thresholds for diagnosis will depend on expert opinion and be based on a consideration of relative risk. ${ }^{19}$ Later, Sermer and colleagues reported that only fasting glucose could be related to macrosomia (birth weight $>4000 \mathrm{~g}$ ). ${ }^{20}$ Similarly, Disse E et al. suggested that $>5.1 \mathrm{mmol} / \mathrm{L}$ cutoff value for fasting glucose was highly predictive for the delivery of large infants. ${ }^{21}$ In contrast Combs et al. showed that rising postprandial glucose values were associated with fetal macrosomia. ${ }^{22}$ Mean while this study revealed that the risk for macrosomia appears to be more strongly associated with GDM.

Generally management includes nutritional therapy, exercise, blood glucose monitoring and insulin therapy. A multicenter randomized study showed that the risk of fetal overgrowth were reduced by treatment. ${ }^{23}$ Insulin is required when dietary treatments fail to achieve near-normal glucose control in GDM women. Duration of dietary measures alone before starting insulin therapy depends on the patient's glycemic control and the baby's gestational age when GDM is diagnosed. Insulin is added for greater control of maternal hyperglycemia where the blood glucose levels remain elevated despite of dietary or exercise management. ${ }^{24}$ The treatment of choice for any type of diabetes in pregnancy is insulin. Most of insulin preparations used today has been proved to be safe and help good glycemic control during pregnancy. Some studies showed that even minimal changes in glucose tolerance can result in abnormal fetal growth which can be prevented by simple control of blood glucose. ${ }^{23,25}$ It is worth mentioning that, many studies showed that diet or exercise can be used to reduce adverse outcomes. Barakat et al. reported that the exercise intervention can reduce macrosomia by $58 \% .{ }^{26}$ We should actively use insulin, and health education to improve maternal compliance so as to avoid severe maternal-fetal complications.

This study elucidates that GDM adverse outcome is inevitable but could be decreased with preventive measures, which showed Cesarean section 36.95\%, preterm delivery $14.13 \%$, polyhydramnios $27.17 \%$ and macrosomia $21.73 \%$. So, careful monitoring of blood glucose levels, dietary control and insulin therapy with their safety profile have been considered the gold standard in the management of GDM. Further prospective studies are required to determine adverse pregnancy outcomes in GDM.

\section{CONCLUSION}

GDM adverse outcome is inevitable in untreated cases but can be reduced by prompt health education, change in life style, dietary control and intensive therapy to keep the patient euglycemic during the entire period of pregnancy. This study demonstrated that the GDM has higher risk for Cesarean section, polyhydramnios, macrosomia and preterm delivery. Early diagnosis of disease, pharmacotherapy and change in daily life style could diminish the adverse effect.

\section{Conflict of interest}

None

\section{REFERENCES}

1. American Diabetes Association. Diagnosis and classification of diabetes mellitus. Diabetes Care. 2009 Jan;32 (Supplement1):S62-S67.

2. American Diabetes Association. Standards of medical care in diabetese-2012. Diabetes Care. 2012 Jan;35(Supplement 1):S11-S63.

3. Getahun D, Fassett MJ, Jacobsen SJ. Gestational diabetes: risk of recurrence in subsequent pregnancies. Am J Obstet Gynecol. 2010 Nov;203(5):467.

4. Bellamy L, Casas JP, Hingorani AD, Williams D. Type 2 diabetes mellitus after gestational diabetes: a systematic review and meta-analysis. Lancet. 2009 May;373(9677):1773-9.

5. Chodick G, Elchalal U, Sella T, Heymann AD, Porath A, Koika E, et al. The risk of overt diabetes mellitus among women with gestational diabetes: a population- based study. Diabet Med. 2010 Jul;27(7): 779-85. 
6. Yogev Y, Visser GH. Obesity, gestational diabetes and pregnancy outcome. Semin Fetal Neonatal Med. 2009 April;14(2):77-84.

7. Vidaeff AC, Yeomans ER, Ramin SM. Gestational diabetes: a field of controversy. Obstet Gynecol Surv. 2003 Nov;58(11):759-69.

8. Brody SC, Harris R, Lohr K. Screening for gestational diabetes: A summary of the evidence for the U.S. preventive services task force. Obstet Gynecol. 2003 Feb;101(2):380-92.

9. Metzger BE, Gabbe SG, Persson B, Buchana TA, Catalano, et al., International Association of Diabetes and Pregnancy Study Groups Consensus Panel. International Association of Diabetes and Pregnancy Study Groups recommendations on the diagnosis and classification of hyperglycemia in pregnancy. Diabetes Care. 2010 Mar;33(3):676-82.

10. HAPO Study Cooperative Research Group. Hyperglycemia and adverse pregnancy outcomes. N Engl J Med 2008 May:358 (19):1991-2002.

11. Peticca P, Keely EJ, Walker MC, Yang Q, Bottomley J. Pregnancy outcomes in diabetes subtypes: how do they compare? A province-based study of Ontario, 2005-2006. J Obstet Gynaecol Can. 2009 Jun;31(6):487-496.

12. Tan PC, Ling LP, Omar SZ. The 50-g glucose challenge test and pregnancy outcome in a multiethnic Asian population at high risk for gestational diabetes. Int J Gynaecol Obstet. 2009 Apr;105(1):50-5.

13. Vink JY, Poggi SH, Ghidini A, Spong CY. Amniotic fluid index and birth weight: is there a relationship in diabetics with poor glycemic control?. Am J Obstet Gynecol. 2006 Sep;195(3):848-50.

14. Idris N, Wong SF, Thomae M, Gardwnwr G, McIntyre DH. Influence of polyhydramnios on perinatal outcome in pregestational diabetic pregnancies. Ultrasound Obstet Gynecol. 2010 Sep;36(3):338-43.

15. Dutta DC. Text book of obstetrics. Chapter 19: medical and surgical illness complicating pregnancy. Sixth edition 2004 ; pp 284-290.

16. Mathiensen ER, Vaz JA. Insulin treatment in diabetic pregnancy. Diabetes Metab Res Rev. 2008 May-Jun;24 (Suppl 2):S3-20.

17. Stotland NE, Caughey AB, Breed EM, Escobar GJ. Risk factors and obstetric complications associated with macrosomia. Int J Gynecol Obstet. 2004 Dec;87(3):220-6.

18. Langer, O. Maternal glycemic criteria for insulin therapy in gestational diabetes mellitus. Diabetes Care. 1998 Aug;21 (suppl 2):B91-8.

19. Sacks DA, Greenspoon JS, Abu-Fadil S, Henry HM, Wolde-Tsadik G, Yao JF. Toward universal criteria for gestational diabe tes: The 75-hour glucose tolerance test in pregnancy. Am J Obstet Gynecol. 1995 Feb;172(2Pt 1):607-14.

20. Sermer M, Naylor CD, Gare DJ, Kenshole AB, Ritchie JW, Farine D, et al. Impact of increasing carbohydrate intolerance on maternal-fetal outcomes in 3637 women without gestational diabetes. The Toronto Tri-Hospital Gestational Diabetes Project. Am J Obstet Gynecol. 1995 Jul;173(1):146-56.

21. Disse E, graeppi-Dulac J, Joncour-Mills G, Dupuis O,Thivolet C. Heterogeneity of pregnancy outcomes and risk of LGA neonates in Caucasian females according to IADPSG criteria for gestational diabetes mellitus. Diabetes Metab. 2013 Apr;39(2):132-8.

22. Combs CA, Gunderson E, Kitzmiller JL, Gavin LA, Main EK. Relationship of fetal macrosomia to maternal postprandial glucose controlduring pregnancy. Diabetes Care. 1992 Oct;15(10):1251-7.

23. Metzger BE, Coustan DR. Summary and recommendations of the fourth international workshop-conference on gestational diabetes mellitus. Diabetes Care. 1998 Aug;21(Suppl 2):B161-7.

24. Landon MB, Spong CY, Thom E, Carpenter MW, Ramin SM, Casey B, et al. A Multicenter, Randomized Trial of Treatment for Mild Gestational Diabetes. N Engl J Med. 2009 Oct;361(14):1339-48.

25. Bonomo M, Corica D, Mion E, Gonclaves D, Motta G, Merati R, et al. Evaluating the therapeutic approach in pregnancies complicated by borderline glucose intolerance: a randomized clinical trial. Diabet Med. 2005 Nov;22(11):1536-41.

26. Barakat R, Pelaez M, Lopez C, Lucia A, Ruiz JR. Exercise during pregnancy and gestational diabetes-related adverse effects: a randomised controlled trial. Br J Sports Med. 2013 Jul;47(10):630-6. 